\title{
Does Education Lead to a Healthier Diet? Evidence From a Natural Experiment
}

\author{
Murat Anil Mercan ${ }^{1}$ \\ ${ }^{1}$ Gebze Technical University, Turkey \\ Correspondence: Murat Anil Mercan, Gebze Technical University, Turkey. Tel: 90-262-605-1429.
}

Received: December 3, 2019

Accepted: January 20, 2020

Online Published: March 5, 2020

doi:10.5430/rwe.v11n1p56

URL: https://doi.org/10.5430/rwe.v11n1p56

\begin{abstract}
The literature suggests that food purchases are significantly affected by the purchaser's level of education. However, endogeneity is an important factor to consider in estimating such effects. In this study, we investigated endogeneity effects on food purchases, using a 1997 change in the laws on compulsory schooling in Turkey to determine the relationship between human capital investment and health. Our data use the Turkish Statistical Institute's (TUIK) Household Budget Survey (HBS) from 2016, a nationally representative dataset. Our results suggest that possession of a middle school diploma increases consumption of fruit, vegetables, and meat but not milk. We find that OLS results suffer from underestimation and that having a middle school education supports having a healthier diet.
\end{abstract}

Keywords: food purchases, education, healthy diet, meat, milk, fruit, vegetable

\section{Introduction}

It is well known that the use of observational data for causal inferences is a challenge in the absence of randomized experiments. A variety of approaches, from regression discontinuity designs to the use of panel data, are employed to evade the difficulties (Auld and Grootendorst, 2011). This issue is also important for estimations of the casual effects of education on diet. Food consumption strongly influences many aspects of life: for instance, the risk of coronary heart disease is reduced when fruit and vegetable (FV) consumption is increased (Gan et al, 2015). In addition, an inverse relationship has been found between obesity and FV consumption, and a negative relationship has been found between depression and FV consumption (Heo et al., 2011; Liu et al., 2016) Therefore, it is essential to increase healthy eating habits. How can this goal be achieved? The answer might be education: for instance, a relationship has been found between parental education and children's food consumption in eight European countries (Miguel Fernandez-Alvira, 2013). That study found that less-educated parents provide sugar-rich and fatty foods to their children, which increases the risk of obesity, while more-educated parents provide foods with less sugar and fat foods.

Many studies have investigated the relationship between education and nutrition and its health effects (Grepin and Bharadwaj, 2015; Hoppu et al., 2018; Kaper et al., 2019), and a few have also investigated the relationship between education and FV consumption (Berning and Hogan, 2014). These have shown that FV purchases are significantly affected by education level. However, endogeneity is an important issue for questions of the effects of education; for instance, individuals with higher financial means may both consume more FV and have a higher education level. Therefore, we must control such effects. In economics, one of the most common methods of overcoming endogeneity problems involves the use of changes in compulsory school laws. As far as we know, this study is the first attempt to employ a compulsory change to school laws to specifically estimate the effects of education on FV, meat, and milk purchases.

Two previous studies have also used a change in compulsory school laws to measure the effects of education on food consumption. Both of those studies used a dummy variable to assess food consumption. Using an instrumental variable and regression discontinuity approaches, researchers found that education did not affect daily fruit consumption in Britain, although the sign of coefficient was positive (Clark and Royer, 2010). In addition, a change in the compulsory school laws in Turkey was used in an unpublished paper in a similar way to what we have done here (Cesur et al., 2014). In that study, it was estimated that the effect of education on FV with two dummy variables equaled one if a person ate fruit or vegetables at least once per day. Further, they found that education did not affect fruit consumption. However, these studies were not explicitly designed to examine the impacts of education on FV purchases. Our study used actual food purchase amounts. 
We used a change in the compulsory schooling laws in Turkey to determine the relationship between human capital investment and health. Our results suggest that having a middle school diploma increases consumption of fruit, vegetables, and meat but not milk.

Even though the positive relationship between education and health outcomes is well documented, the endogeneity problem remains an issue. Several studies have used an instrumental variable approach, with a change in compulsory school laws as the instrument. For example, compulsory education laws from 1915 to 1939 were used as instruments for education, and a negative relationship was found between education and mortality in the United States (Lleras-Muney, 2005). In that study, interestingly, no evidence was found that education is endogenous for the mortality equation. In a separate study of Dutch compulsory school laws, a significant negative effect on mortality was found for education (van Kippersluis et al., 2011). However, no significant effect was found on mortality from education using changes in compulsory school laws in France (Albouy and Lequien.

The effects of compulsory schooling years on obesity were estimated in nine European countries for females and seven European countries for males (Brunello et al., 2013). These studies found that education reduces body mass index (BMI) in women but not in men. Additionally, a new study estimated the effects of education on smoking, drinking, exercising, and BMI in 13 European countries (Brunello et al., 2016) and found that education has a protective effect on older European men and women. Changes in compulsory schooling laws were examined for West German data between 1949 and 1969 (Kemptner et al., 2011), for the effects of education on long-term illness, obesity, and smoking. The results of these studies show that education reduces long-term illness in men but not women and does not impact smoking.

A researcher reviewed Danish school reforms between 1958 and 1975 while investigating the effect of education on self-reported health, BMI, and smoking (Arendt, 2005)]. He found a positive impact on these variables. In addition, another researcher used a Swedish comprehensive school reform from 1950 as an instrument and produced similar results (Spasojević, 2010). Additionally, changes in compulsory schooling laws in the UK were used to investigate the effects of education on health (Powdthavee, 2010; Silles, 2009)]. Both of these studies found a significant positive effect for education. On the other hand, another study did not find a statistically significant effect for changes in compulsory schooling laws in the UK (Jurges, 2013).

Finally, two researchers used three different datasets, including the Health and Retirement Study (HRS) in the US, the English Longitudinal Study of Ageing (ELSA) in the UK, and the Study of Health, Ageing and Retirement in Europe (SHARE), for people 50 years or older in 13 member countries of the Organization for Economic Co-operation and Development (OECD) (Fonseca and Zheng, 2011). They took variation in the timing of educational reforms as an instrument to test the effects of education on self-reported health and the occurrence of both diabetes and hypertension. They found positive significant effects on those variables.

\section{Materials and Methods}

\subsection{The 1997 Reform of Compulsory Schooling in Turkey}

In August 1997, the Turkish Parliament increased mandatory education from five to eight years. This law went into effect immediately in the fall of 1997. Students who were enrolled in the fifth grade in fall 1997 were required to continue their schooling until the end of the eighth grade. However, students who had already completed the fifth grade by the summer of 1997 were not subject to that requirement.

It should be noted that although the age at which primary school should begin is mandated by Turkish law (72 months of age at the end of the calendar year) it is not strictly enforced (Cesur et al., 2014). Therefore, those who were born in early 1986 could begin first grade in the fall of 1991 instead of the fall of 1992. Even though the results were not affected, we did not include people born in 1986 in our analysis, as previous studies have done (Dursun and Cesur, 2016; Dursun et al., 2018).

\subsection{Data}

Data from the Turkish Statistical Institute's (TUIK) Household Budget Survey (HBS) from 2016 were used in this study. The HBS is a nationally representative dataset. Each year, it surveys more than 10,000 households. HBS data are well-suited for this study for several reasons, including the fact that they are taken from a national probability sample. Therefore, they avoid sample homogeneity. Additionally, consumption values in HBS are clearly observable as five-digit codes. As such, it is easy to conduct an analysis of the effects of education on food consumption.

In HBS-2016, the variable for education level variable comprises 12 categories: no schooling completed, primary school (requiring 5 years of education to complete), primary education, secondary school, junior vocational high 
school, high school, senior vocational high school, 2 or 3 years of college, 4 years of college or university, faculties for 5 or 6 years e.g. a professional degree such as a law degree, a master's degree, or a doctoral degree.

Our analysis distinguished between those with more than 5 years of schooling and those with equal or less. We defined middle school graduates as those who are in the primary education, secondary school, junior vocational high school, high school, senior vocational high school, 2 or 3 years of college, 4 years college or university, professional degrees, a master's degree, or a doctoral degree categories.

We also created an education variable describing to the years of schooling required for each aforementioned category. That variable equaled 0 for no schooling completed, 5 for primary school, 8 for primary education, secondary school, and junior vocational high school, 12 for high school and senior vocational high school, 14 for 2 or 3 years of college, 16 for 4 years of college or university, and 18 for faculties for 5 or 6 years and master's degree, and 22 for doctoral degree.

HBS includes data on household expenditures for FV, meat, and milk. However, our analysis required individual purchase amounts. To this end, we followed Berning and Hogan's (2014) approach (Berning and Hogan, 2014). Specifically, we divided household expenditures by total household size.

Table 1 presents the summary statistics for the FV sample from our IV analysis. The average monthly FV purchase was 39.88 Turkish lira, or approximately U.S. $\$ 13.20$ (the average exchange rate between the Turkish lira and US dollar in 2016 was 3.03). According to the table, 44 percent of the sample was male, and 54 percent had a middle school diploma. Furthermore, 60 percent of the sample was married. In addition, the average years of schooling were around 8 years (7.95), according to the education variable we created. The average age was around 44, and average yearly income was around 16,900 Turkish lira, or approximately US\$5,578. Finally, 27 percent of the sample was affected by the 1997 compulsory schooling reform.

Table 1. Summary Statistics for the FV sample from IV analysis

\begin{tabular}{lcccc}
\hline & Mean & S.D. & Min & Max \\
\cline { 2 - 5 } Value of Fruit and Vegetable Consumption & 39.88 & 54.30 & 0.35 & 2430 \\
Middle School Dummy & 0.54 & 0.50 & 0 & 1 \\
Years of Schooling & 7.08 & 4.83 & 0 & 18 \\
Male & 0.45 & 0.50 & 0 & 1 \\
Married & 0.60 & 0.49 & 0 & 1 \\
Age & 44.42 & 18.37 & 15 & 99 \\
Total Income & 16,851 & 23,061 & 0 & 813,400 \\
Disabled & 0.05 & 0.22 & 0 & 1 \\
Reform Dummy & 0.27 & 0.44 & 0 & 1 \\
& & & & \\
$\mathrm{n}$ & & & & \\
\end{tabular}

\subsection{The Model}

To determine the relationship between food consumption and education, we used the following regression formula:

$$
\text { Food Consumption }=\alpha+\beta \text { Middle School }+\mathrm{A}+\varepsilon \text {, }
$$

In equation 1, Food Consumption represents the purchase amounts of FV, meat, or milk; Middle School is a binary variable indicating holding at least a middle school degree; and $\mathrm{A}$ is a set of control variables, including age, age squared, married dummy, male dummy, work limitations due to health dummy, and total income. However, the use of OLS causes bias for the $\beta$ estimate due to the possible endogeneity problem. Therefore, we used an instrumental variable (IV) strategy, and our IV was exposure to educational reform. To this end, we applied the following IV method:

$$
\text { Middle School }=\mu+\gamma \text { Reform }+B+\xi \text {, }
$$


In equation 2, Reform is a binary variable measuring how people were affected by the educational reform of 1997, equaling 1 for people born after 1986 and 0 for people born before 1986. As in the study by Cesur et al. (2014), we omitted the birth cohort of 1986 from the regression because we could not be certain who was affected by the reform (1).

\section{Results}

Table 2 reports the estimates drawn from both the OLS and IV methods for FV consumption. The OLS model was considered likely to be biased, and its coefficient was -0.57 (S.E.: 0.45). This result indicates that having a middle school diploma decreases FV consumption. However, it is was not reliable due to the endogeneity problem. Therefore, to estimate the casual relationship between education and FV consumption, we examined our IV results.

According to Table 2, when we used the educational reform of 1997 as an IV, we estimated a positive coefficient for having a middle school diploma, at 0.43 (SE: 0.14). This finding suggests that having a middle school diploma increases FV consumption, and OLS presents significantly underestimated results. Our estimate correlation is highly significant and suggests we indeed must account for the endogeneity problem in the estimates. Our results imply that formal education increases FV consumption, leading to a healthier diet.

Table 2. Results for fruit and vegetable consumption

\begin{tabular}{lcccc}
\hline & \multicolumn{2}{c}{ OLS } & \multicolumn{2}{c}{ IV } \\
\cline { 2 - 5 } Middle School Dummy & Coefficient & S.E. & Coefficient & S.E. \\
\cline { 2 - 5 } Male & $-0.57^{* * *}$ & 0.45 & $0.43 * * *$ & 0.14 \\
Married & $0.34^{* * *}$ & 0.04 & $0.33^{* * *}$ & 0.04 \\
Age & $0.23^{* * *}$ & 0.04 & $0.28^{* * *}$ & 0.05 \\
Square of Age & $-0.05^{* * *}$ & 0.01 & $-0.02^{* * *}$ & 0.01 \\
Total Income & $0.00^{* * *}$ & 0.00 & $0.00^{* * * *}$ & 0.00 \\
Disabled & $0.00^{* * *}$ & 0.00 & $0.00^{* * *}$ & 0.00 \\
Constant & 0.16 & 0.13 & 0.17 & 0.13 \\
& $5.09^{* * *}$ & 0.16 & $-27.07 * *$ & 4.33 \\
Reform & & & & \\
Constant & & & $0.55^{* * * *}$ & 0.00 \\
Corr (e.middleschool,e.FV) & & & $0.39^{* * *}$ & 0.00 \\
& & & $-0.13^{* * *}$ & 0.02 \\
\hline
\end{tabular}

$* * * \overline{p<0.01 * * \quad p<0.05 * p<0.10}$

Table 3 reveals similar results for meat consumption. In Table 3, it can be seen that when the educational reform of 1997 is used as an IV, a positive, large coefficient was estimated for having a middle school diploma, namely 0.79 (SE: 0.54 ), but OLS produced -0.77 (SE: 0.14). This suggests that having a middle school diploma also increases meat consumption, and OLS gives a lower bound for estimates. In addition, estimate correlation was again highly significant, suggesting that endogeneity must indeed be accounted for in estimates.

Table 3. Results for meat consumption

\begin{tabular}{lcccc}
\hline & \multicolumn{2}{c}{ OLS } & \multicolumn{2}{c}{ IV } \\
\cline { 2 - 5 } Middle School Dummy & Coefficient & S.E. & Coefficient & S.E. \\
\cline { 2 - 5 } Male & $-0.77^{* * *}$ & 0.14 & 0.79 & 0.54 \\
Married & 0.11 & 0.12 & 0.12 & 0.13 \\
\hline
\end{tabular}




\begin{tabular}{lcccc}
\hline Age & $-0.04 * *$ & 0.02 & $0.02^{* * *}$ & 0.03 \\
Square of Age & $0.00^{* * *}$ & 0.00 & 0.00 & 0.00 \\
Total Income & 0.00 & 0.00 & 0.00 & 0.00 \\
Disabled & $-0.83^{* * *}$ & 0.26 & $-0.81^{* * *}$ & 0.26 \\
Constant & $4.50^{* * *}$ & 0.38 & $2.14 * * *$ & 0.86 \\
& & & & \\
Reform & & & $0.49^{* * *}$ & 0.01 \\
Constant & & & $0.45^{* * *}$ & 0.01 \\
Corr (e.middleschool,e.Meat) & & & $-0.09^{* * *}$ & 0.03 \\
& 17,856 & & 17,491 & \\
\hline
\end{tabular}

$* * * \overline{p<0.01 * * \quad p<0.05 * p<0.10}$

Table 4 shows our estimates for milk consumption. The estimate correlation was not significant at usual levels, suggesting that is would not be necessary to consider the effects of the endogeneity problem for the estimates. The effects of underestimation of OLS was greatest for meat consumption. The OLS results show that having a middle school diploma decreases milk consumption. We should point out that the sample size of milk consumption estimates is significantly smaller. This might be a reason why milk consumption exhibited a different sign and the endogeneity problem did not appear in the analysis. Therefore, these results should be interpreted with caution.

Table 4. Results for milk consumption

\begin{tabular}{|c|c|c|c|c|}
\hline & \multicolumn{2}{|c|}{ OLS } & \multicolumn{2}{|l|}{ IV } \\
\hline & Coefficient & S.E. & Coefficient & S.E. \\
\hline Middle School Dummy & $-0.07 * * *$ & 0.02 & -0.03 & 0.06 \\
\hline Male & $0.04 * * *$ & 0.01 & $0.04 * * *$ & 0.02 \\
\hline Married & $0.07 * * *$ & 0.02 & $0.07 * * *$ & 0.02 \\
\hline Age & $-0.01 * * *$ & 0.00 & -0.01 & 0.00 \\
\hline Square of Age & $0.00 * * *$ & 0.00 & $0.00 * * *$ & 0.00 \\
\hline Total Income & $0.00^{* * *}$ & 0.00 & $0.00^{* * *}$ & 0.00 \\
\hline Disabled & $0.07 * *$ & 0.04 & $0.08 * *$ & 0.04 \\
\hline Constant & $0.60^{* * *}$ & 0.05 & $2.14 * * *$ & 0.86 \\
\hline Reform & & & $0.53^{* * *}$ & 0.01 \\
\hline Constant & & & $0.42 * * *$ & 0.01 \\
\hline \multirow[t]{2}{*}{ Corr (e.middleschool,e.Milk) } & & & -0.02 & 0.04 \\
\hline & \multicolumn{2}{|c|}{9,336} & \multicolumn{2}{|l|}{9,147} \\
\hline
\end{tabular}

$* * * \overline{p<0.01 * * \quad p<0.05 * p<0.10}$

\section{Discussion}

According to TUIK's Turkey Health Interview Survey, in 2016, about 24 percent of women and 15 percent of men in Turkey were found to be obese. Obesity, is related to nutrition and premature death and is an important public issue (Mercan, 2014). Therefore, our estimates have several important implications for both the assessment of previous literature and policy suggestions. Our results suggest that previous studies likely underestimated the effects of education on healthy food intake. For example, there have been several studies that investigated the effects of nutrition education on food consumption, and an extensive review of the literature showed that interventions are more effective 
when few other choices are available in places of purchase (Seymour et al., 2004). Another study, which used a dataset of African Americans in rural Missouri found that educational interventions are effective (Barnidge et al., 2015).

Several other studies have investigated the relationship between food intake and education; for example, researchers using Portuguese data have found that education increases the odds of milk, vegetable soup, vegetable, fruit, and fish consumption (Moreira and Padrão, 2004) . It has also been found that inflation-adjusted per capita expenditures on fruits and vegetables increased by $\$ 0.44$ between 1991 and 2000 (from $\$ 5.55$ in 1991) for US households headed by someone with 4 or more years of college (Blisard et al., 2004). They concluded that college-educated Americans have been a driving force in increases in fruit and vegetable expenditures between 1991 and 2000.

Two researchers also used a dummy for education level (whether the head of household had attended college) in the 1987-88 Nationwide Food Consumption Survey (NFCS). They concluded that households headed by a college-educated person paid a significantly higher unit value for all foods, except for eggs, than other household types did (Huang and Lin, 2000). Another study studied the annual purchases of households at retail food stores in 1999 (Stewart et al., 2004). They found that in the US, households with college-educated heads bought a slightly greater variety of vegetables than do other households (Øvrum, 2011). Demand for FV was estimated using latent class models and individual-level data from the Norwegian Monitor Survey, indicating that education positively affected demand for FV.

There have been few studies of developing countries, with one notable exception, which focused on FV consumption in Malaysia (Yen et al., 2011). That study found that more-educated people were inclined to make healthy diet choices and ate more FV than less-educated people.

Furthermore, our results suggest that formal education may play an important role in healthy diet decisions. Therefore, when policy is crafted to fight with illnesses related to unhealthy dietary habits, formal education must be considered very important and particularly useful for better policies.

In addition, to measure causality accurately, researchers may use machine learning methods e.g. LASSO. We believe that those approaches may give new opportunities to researchers estimating the causality.

\section{Conclusions}

Although the relationship between food consumption and education have been examined, those studies have usually suffered from endogeneity problems. To overcome this, we used an IV approach, using educational reform in Turkey as the IV.

Our results suggest that OLS results suffer from underestimation and that having a middle school diploma increases fruit, vegetable, and meat consumption but not milk consumption. Although this study is the first attempt to use changes in compulsory schooling laws to estimate the relationship between the actual purchase amounts of FV, meat, and milk and education, it has some shortcomings; e.g., we used a cross-section of data instead of a panel dataset. In addition, our sample size was smaller for the samples of meat consumption and milk consumption. Therefore, to obtain better estimates, future studies must use larger samples for those.

Another important research area might be investigating other food products that are consumed frequently e.g. rice, pasta or sugar. Furthermore, researchers might estimate the weight of each food products in the budget of households.

Finally, this study sheds light on the relationship between human capital investments and healthy eating habits. It is especially important for the design of better policies.

Funding: This research received no external funding.

Conflicts of Interest: The author declares no conflict of interest

\section{References}

Albouy, V., \& Lequien, L. (2009). Does compulsory education lower mortality? J Health Econ, 28, 155-168.

Arendt, J. N. (2005). Does education cause better health? A panel data analysis using school reforms for identification. Economics of Education Review, 24, 149-160.

Auld, M. C., \& Grootendorst, P. (2011). Challenges for causal inference in obesity research. In The oxford handbook of the social science of obesity.

Barnidge, E. K., Baker, E. A., Schootman, M., Motton, F., Sawicki, M., \& Rose, F. (2015). The effect of education plus access on perceived fruit and vegetable consumption in a rural african american community intervention. Health Education Research, 30, 773-785. 
Berning, J., \& Hogan, J. J. (2014). Estimating the impact of education on household fruit and vegetable purchases. Applied Economic Perspectives and Policy, 36, 460-478.

Blisard, N., Stewart, H., \& Jolliffe, D. (2004). Low-income households' expenditures on fruits and vegetables. Agricultural Economic Report.

Brunello, G., Fabbri, D., \& Fort, M. (2013). The causal effect of education on body mass: Evidence from europe. Journal of Labor Economics, 31, 195-223.

Brunello, G., Fort, M., Schneeweis, N., \& Winter-Ebmer, R. (2016). The causal effect of education on health: What is the role of health behaviors?. Health Econ, 25, 314-336.

Cesur, R., Dursun, B., \& Mocan, N. (2014). The impact of education on health and health behavior in a middle-income, low-education country. National Bureau of Economic Research.

Clark, D., \& Royer, H. (2010). The effect of education on adult health and mortality: Evidence from britain. National Bureau of Economic Research.

Dursun, B., \& Cesur, R. (2016). Transforming lives: The impact of compulsory schooling on hope and happiness. $J$ Popul Econ, 29, 911-956.

Dursun, B., Cesur, R., \& Mocan, N. (2018). The impact of education on health outcomes and behaviors in a middle-income, low-education country. Economics \& Human Biology, 31, 94-114.

Fonseca, R., \& Zheng, Y. (2011). The effect of education on health: Cross-country evidence. RAND Working Papers.

Gan, Y., Tong, X. Y., Li, L. Q., Cao, S. Y., Yin, X. X., Gao, C., ... Chen, Y. W. (2015). Consumption of fruit and vegetable and risk of coronary heart disease: A meta-analysis of prospective cohort studies. Int J Cardiol, 183, 129-137.

Grepin, K. A., \& Bharadwaj, P. (2015). Maternal education and child mortality in zimbabwe. J Health Econ, 44, 97-117.

Heo, M., Kim, R. S., Wylie-Rosett, J., Allison, D. B., Heymsfield, S. B., \& Faith, M. S. (2011). Inverse association between fruit and vegetable intake and bmi even after controlling for demographic, socioeconomic and lifestyle factors. Obesity Facts, 4, 449-455.

Hoppu, U., Puputti, S., Aisala, H., Laaksonen, O., \& Sandell, M. (2018). Individual differences in the perception of color solutions. Foods, 7, 8.

Huang, K., \& Lin, B. (2000). Estimation of food demand and nutrient elasticities from household survey data. USDA Technical Bulletin No. (TB-1887).

Jurges, H., Kruk, E., \& Reinhold, S. (2013). The effect of compulsory schooling on health-evidence from biomarkers. J Popul Econ, 26, 645-672.

Kaper, M. S., de Winter, A. F., Bevilacqua, R., Giammarchi, C., McCusker, A., Sixsmith, J., ... Reijneveld, S. A. (2019). Positive outcomes of a comprehensive health literacy communication training for health professionals in three european countries: A multi-centre pre-post intervention study. Int J Env Res Pub He, 16.

Kemptner, D., Jurges, H., \& Reinhold, S. (2011). Changes in compulsory schooling and the causal effect of education on health: Evidence from germany. J Health Econ, 30, 340-354.

Liu, X. Q., Yan, Y., Li, F., \& Zhang, D. F. (2016). Fruit and vegetable consumption and the risk of depression: A meta-analysis. Nutrition, 32, 296-302.

Lleras-Muney, A. (2005). The relationship between education and adult mortality in the united states. Review of Economic Studies, 72, 189-221.

Mercan, M. A. (2014). A research note on the relationship between long working hours on weight gain for older workers in the united states. Res Aging.

Miguel Fernandez-Alvira, J., Mouratidou, T., Bammann, K., Hebestreit, A., Barba, G., Sieri, S., ... Kovacs, E. (2013). Parental education and frequency of food consumption in european children: The idefics study. Public Health Nutrition, 16, 487-498.

Moreira, P. A., \& Padrão, P. D. (2004). Educational and economic determinants of food intake in portuguese adults: A cross-sectional survey. Bmc Public Health, 4, 1-11.

Øvrum, A. (2011). Socioeconomic status and lifestyle choices: Evidence from latent class analysis. Health Econ, 20, 
971-984.

Powdthavee, N. (2010). Does education reduce the risk of hypertension? Estimating the biomarker effect of compulsory schooling in england. J Hum Capital, 4, 173-202.

Seymour, J. D., Yaroch, A. L., Serdula, M., Blanck, H. M., \& Khan, L. K. (2004). Impact of nutrition environmental interventions on point-of-purchase behavior in adults: A review. Prev Med, 39, 108-136.

Silles, M. A. (2009). The causal effect of education on health: Evidence from the united kingdom. Economics of Education Review, 28, 122-128.

Spasojević, J. (2010). Chapter 9 effects of education on adult health in sweden: Results from a natural experiment. In Current issues in health economics, pp. 179-199.

Stewart, H., Harris, M., \& Guthrie, J. (2004). What determines the variety of a household's vegetable purchases?. USDA Agriculture Information Bulletin No. (AIB-792-3).

van Kippersluis, H., O'Donnell, O., \& van Doorslaer, E. (2011). Long-run returns to education does schooling lead to an extended old age?. J. Hum. Resour., 46, 695-721.

Yen, S. T., Tan, A. K. G., \& Nayga, R. M., Jr. (2011). Determinants of fruit and vegetable consumption in malaysia: An ordinal system approach. Australian Journal of Agricultural and Resource Economics, 55, 239-256. 